\title{
Conditional probability of reinforcement and sequential behavior in human conditioning with intermittent reinforcement schedules'
}

\author{
WILLIAM F. PROKASY and KAROL L. KUMPFER, \\ University of Utah, Salt Lake City, Utah 84112
}

Fourteen Ss were exposed to three 50\%-reinforcement schedules in human eyelid conditioning. The schedules differed in that the likelihood of a reinforced (nonreinforced) trial following a reinforced (nonreinforced) trial was either.3, .5 , or .7. At .7 during early training, there was evidence of greater increments and decrements following successive reinforced and nonreinforced trials, respectively. During late training, there were no differential effects of the conditional probability of reinforcement; rather, there was little evidence of any sequential behavior contingent on successive reinforcements, suggesting that the parameters of a linear operator model modify with extended training.

In the typical $50 \%$ reinforcement schedule the conditional probability of a reinforced trial following a reinforced trial, $P(R \mid R)$, as well as the conditional probability of a nonreinforced trial following a nonreinforced trial, $P(\bar{R} \mid R)$, is .5. When both $\mathbf{P}(\mathbf{R} \mid \mathbf{R})$ and $P(\bar{R} \mid \bar{R})$ are increased (maintaining the $50 \%$ reinforcement ratio) increments and decrements in response probability following, respectively, reinforced and nonreinforced trials are larger, but they are smaller when $\mathbf{P}(\mathbf{R} \mid \mathbf{R})$ and $\mathbf{P}(\bar{R} \mid \bar{R})$ are less than .5 (Prokasy, Carlton, \& Higgins, 1967; Higgins \& Prokasy, 1968). The purpose of this study was to extend these observations by determining (a) if differential sequential effects could be obtained when the same Ss are exposed to different values of $\mathbf{P}(\mathbf{R} \mid \mathbf{R})$ and $\mathbf{P}(\bar{R} \mid \bar{R})$ in different sessions and (b) whether the sequential effects would be maintained with extensive training. In all cases, $P(R \mid R)=P(\bar{R} \mid \bar{R})$.

\section{METHOD}

The method of transducing and recording eyelid responses is reported elsewhere (Prokasy et al, 1967). The CS was a $600-\mathrm{msec}, 1000-\mathrm{Hz}$ tone, the interstimulus interval was $600 \mathrm{msec}$, and the UCS was a $50-\mathrm{msec}$ puff of nitrogen of sufficient intensity to support a $150-\mathrm{mm}$ column of mercury. A total of $14 \mathrm{Ss}$, paid for their services, served in 15 conditioning sessions of 360 trials each. The first 10 trials of each session were composed of five CS-alone and UCS-alone trials. The average intertrial interval was $10 \mathrm{sec}$, varying from 6 to $14 \mathrm{sec}$. Three $50 \%$-reinforcement schedules were employed, these differing only in that $P(R \mid R)=.3, .5$, or .7. The three schedules were randomized over sessions so that each $S$ received five sessions at each $P(R \mid R)$ value in an unsystematic order. Through a scheduling error, two $\mathrm{Ss}$ received six sessions of the .7 schedule and only four of the .3 schedule. Also, for two Ss the original data for one of the .7 schedules were misplaced and, consequently, not employed in the analyses. All Ss received standard instructions (i.e., to relax and let their responses take care of themselves) for each session.

\section{RESULTS AND DISCUSSION}

The basic analyses were conducted on sequential behavior. Response probability following either zero, one, two, or three successive reinforcements was calculated for the first and last halves of training. These calculations were performed separately for the three different $P(R \mid R)$ values, thus permitting a comparison of the first two-and-a-half sessions with the last two-and-a-half sessions for each of the three kinds of schedule. The summary data are provided in Table 1.
In the first half of training, response probability increased with successive reinforcements and decreased with successive nonreinforcements, $F(3,39)=10.21$ and 9.66 , respectively. Though there were no overall mean differences as a function of $P(R \mid R)$, Table 1 does illustrate the interaction of $P(R \mid R)$ and Sequence over reinforced trials in the first half of training: The increments in response probability were greater when $P(R \mid R)=.7$ than when it equalled .3 or $.5, F(6,78)=2.42$. The same interaction is suggested by Table 1 for the nonreinforcement sequence, but it was not statistically reliable, $F(6,78)=1.94$. Response latency (data not shown) decreased reliably with successive reinforcements, but did not change with successive nonreinforcements, $F(3,39)=12.15$ and 2.39 , respectively.

In the second half of training, there were no overall mean differences as a function of $P(R \mid R)$ and no differential sequential effects contingent on $P(R \mid R)$. The only effects obtained were a small decrease in response probability with successive nonreinforcements, $F(3,39)=3.98$, and a decrease in response latency with successive reinforcements. $F(3,39)=3.40$. The latter appeared even though there were no reliable changes in response probability across successive reinforced trials.

These data confirm, this time on a within-Ss basis, earlier observations (Prokasy, Carlton, \& Higgins, 1967; Higgins \& Prokasy, 1968) that variations in $P(R \mid R)$ affect the fine-grain structure of human conditioning performance, but have little effect on overall response probability.

Of more interest are the implications of the data for the application of incremental-decremental models of conditioning. The sequential behavior observed in earlier studies (Prokasy et al, 1967; Higgins et al, 1968) is consistent with the hypothesis that response probability increases with successive reinforcements and decreases with successive nonreinforcements. These outcomes are precisely what would be expected from an incremental-decremental model (e.g., Bush \& Mosteller, 1951; Spence, 1936). However, the evidence showed clearly that the parameters of such a model were established in early training as $S$ gained experience with the specific schedule. A reasonable question is whether the parameters, once established in early training, then remain constant over trials. The evidence of this study suggests not; rather, the parameters appear to modify over many hundreds of trials. The failure to obtain increments with reinforcement

Table 1

Response Probability in the First and Second Halves of Training following Zero, One, Two, or Three Successive Reinforced or Nonreinforced Trials as a Function of $P(R \mid R)$

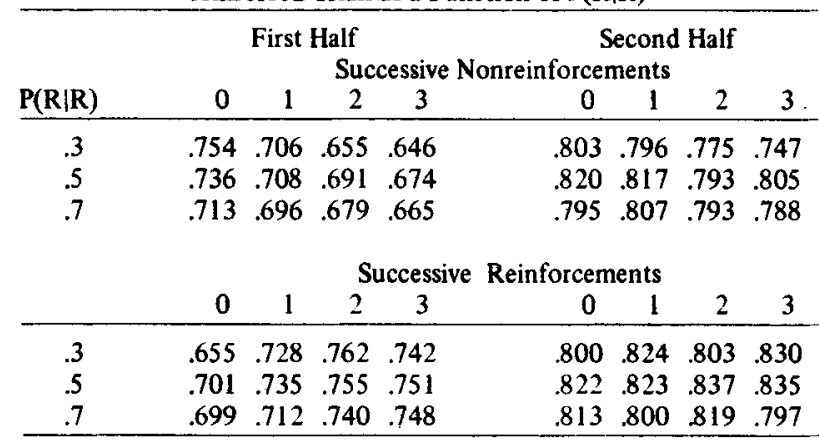


sequences and the small decrements obtained with nonreinforcement sequences in the last half of training indicate changing parameters.

From the framework of a two-operator, linear operator model (Bush \& Mosteller, 1951), there are two possibilities: Either the incremental-decremental parameters are approaching zero or the limit of the operator applied on nonreinforced trials is increasing, gradually approaching the limit of the operator applied on reinforced trials. Regardless of which, or both, two consequences are apparent: A two-operator, linear operator model with static parameter values is, at best, an approximate description of the data.

In a more general context, Prokasy \& Allen (in press) noted that the sequential behavior observed in differential eyelid conditioning is sufficiently similar to that of intermittent reinforcement to suggest that intermittent reinforcement is a special case of differential conditioning in which the CS+ and CS- are indistinct. This position receives additional support from the present study. Response latency decreased following successive reinforced trials, and did not change following successive nonreinforced trials. Prokasy and Allen found a parallel effect with sequences of $\mathrm{CS}+$ and $\mathrm{CS}-$ trials in differential conditioning.

Finally, the data raise questions about the general adequacy of the construct of inhibition of delay to account for latency data. Pavlov (1927, p. 235) reported that with continued training the salivary CR increased in latency. In contrast, CR latency in humans (Ebel \& Prokasy, 1964) and rabbits (Gormezano, Schneiderman, Deaux, \& Fuentes, 1962) decreases over trials. Also, response latency decreases with successive reinforcements (Prokasy \& Allen, in press; this study) and remains constant with successive nonreinforcements. None of these outcomes with the eyelid reflex support the construct of inhibition of delay.

\section{REFERENCES}

BUSH, R. R., \& MOSTELLER, F. A model for stimulus generalization and discrimination. Psychological Review, 1951, 58, 413-423.

EBEL, H. C., \& PROKASY, W. F. Classical eyelid conditioning as a function of sustained and shifted interstimulus intervals. Joumal of Experimental Psychology, 1963, 65, 52-58.

HIGGINS, J. D. The effects of transition probability of reinforcement in intermittent reinforcement schedules in human eyelid conditioning. Psychonomic Science, 1968, 12, 69-70.

GORMEZANO, I., SCHNEIDERMAN, N., DEAUX, E., \& FUENTES, I. Nictitating membrane: Classical conditioning and extinction in the albino rabbit. Science, $1962,138,33-34$.

PROKASY, W. F., \& ALLEN, C. K. Instructional sets in human differential eyelid conditioning. Journal of Experimental Psychology, in press.

PROKASY, W. F., CARLTON, R. A., \& HIGGINS, J. D. Effects of nonrandom intermittent reinforcement schedules in human eyelid conditioning. Journal of Experimental Psychology, 1967, 74, 282-288

PAVLOV, I. P. Conditioned reflexes. Translated by G. V. Anrep. London: Oxford University Press, 1927.

SPENCE, $K$. W. The nature of discrimination learning in animals. Psychological Review, 1936, 43, 437-449. NOTE

1. This study was supported by funds from NSF Grant 5627 and by funds provided by the University of Utah Research Committee. The aid of George E. Armstrong and of Betty Jean -Smith is gratefully acknowledged.

\section{ERRATUM}

STANDING, L. G., \& HABER, R. N. Visual search and memory under degraded and masked presentation. Psychonomic Science, 1968,13 (2), 81-82.-On page 82, in the correction formula, the equals $\Leftrightarrow$ sign following the term $\mathrm{Pg}$ $\mathrm{n} / 4$ should have been a minus $(-)$ sign. 